\title{
Curso de aplicação experimental da escala pedagógica HaSA: relatos sobre as práticas baseadas em evidências na educação inclusiva
}

\author{
HaSA pedagogical scale experimental application course: reports on evidence-based practices in \\ inclusive education
}

Curso sobre la aplicación experimental de la escala pedagógica HaSA: informes sobre prácticas basadas en evidencias en educación inclusiva

\author{
Amanda da Silva Pereira Torres \\ ORCID: https://orcid.org/0000-0001-7812-2516 \\ Universidade Federal Fluminense, Brasil \\ E-mail: torresp.amanda@gmail.com \\ Viviane de Oliveira Freitas Lione \\ ORCID: https://orcid.org/0000-0003-4225-698X \\ Universidade Federal do Rio de Janeiro, Brasil \\ E-mail: vivianelione@gmail.com \\ Vera Lúcia Prudência dos Santos Caminha \\ ORCID: https://orcid.org/0000-0002-6579-6519 \\ Universidade Federal Fluminense, Brasil \\ E-mail: veraprudencia@id.uff.br
}

\begin{abstract}
Resumo
No ensino inclusivo, tem se discutido que agentes educacionais devem estar devidamente capacitados para a prática educacional que alcance as mais diversas necessidades do aluno com deficiência. Para que se alcance esse feito, dependese, cada vez mais, de formações práticas, através de protocolos de avaliação, que viabilize aos agentes educacionais o conhecimento da neurodiversidade que contempla seu aluno. O presente artigo tem como finalidade, avaliar o uso da Escala Pedagógica de Avaliação das Habilidades Sociais e Acadêmicas para Alunos com TEA - HaSA, através da experiência de uma formação continuada para capacitação de agentes educacionais de uma Unidade Municipal de Educação Infantil do Município de Niterói. A escala HaSA, foi elaborada como produto de conclusão do Mestrado Profissional em Diversidade e Inclusão pela Universidade Federal Fluminense com a finalidade de avaliar as habilidades de aprendiz do aluno com transtorno do espectro autista a partir de materiais já reconhecidos e validados. Participaram do estudo, a vice-diretora da unidade educacional, professores regentes, professores de apoio e professor de apoio especializado. A formação foi organizada através de uma introdução teórica básica sobre o TEA, apresentação da escala, sua aplicação e análise dos dados. Busca-se a partir do estudo da escala HaSA, inserir no contexto da educação, intervenções que tenham evidências de eficácia, integrando a experiência educacional com a melhor evidência externa, sendo respeitados os atributos necessários para que seja definido como evidência científica. São caminhos empíricos, potencialmente eficazes, até que se prove o contrário, capazes de transpor as barreiras da mera matrícula do aluno com TEA.
\end{abstract}

Palavras-chave: Ensino; TEA; Escala de avaliação; Práticas baseadas em evidências; Educação inclusiva.

\begin{abstract}
In inclusive education, it has been discussed that educational agents must be properly trained for educational practice that meets the most diverse needs of students with disabilities. In order to achieve this feat, it depends, increasingly, on practical training, through assessment protocols, which enable educational agents to know the neurodiversity that contemplates their student. This article aims to evaluate the use of the Pedagogical Assessment Scale of Social and Academic Skills for Students with ASD - HaSA, through the experience of continuing education to train educational agents of a Municipal Unit of Early Childhood Education in the Municipality of Niterói . The HaSA scale was developed as a result of the completion of the Professional Master's Degree in Diversity and Inclusion by the Fluminense Federal University, with the purpose of evaluating the apprentice skills of students with autism spectrum disorder, using materials that are already recognized and validated. The deputy director of the educational unit, regent teachers, support teachers and specialized support teachers participated in the study. The training was organized through a basic theoretical introduction about the TEA, presentation of the scale, its application and data analysis. Based on the study of the HaSA scale, the aim is to insert interventions that have evidence of effectiveness in the context of education, integrating the educational experience with the best external
\end{abstract}


evidence, respecting the necessary attributes to be defined as scientific evidence. These are empirical paths, potentially effective, until proven otherwise, capable of overcoming the barriers of mere enrollment of the student with ASD.

Keywords: Teaching; ASD; Rating scale; Evidence-based practices; Inclusive education.

\section{Resumen}

En educación inclusiva se ha discutido que los agentes educativos deben estar debidamente capacitados para la práctica educativa que llegue a las más diversas necesidades de los estudiantes con discapacidad. Para lograr esta hazaña, depende, cada vez más, de la formación práctica, a través de protocolos de evaluación, que permitan a los agentes educativos conocer la neurodiversidad que contempla su alumno. Este artículo tiene como objetivo evaluar el uso de la Escala de Evaluación Pedagógica de Habilidades Sociales y Académicas para Estudiantes con TEA - HaSA, a través de la experiencia de educación continua para formar agentes educativos de una Unidad Municipal de Educación Infantil en el Municipio de Niterói. La escala HaSA fue desarrollada como resultado de la realización del Máster Profesional en Diversidad e Inclusión por la Universidad Federal Fluminense, con el propósito de evaluar las habilidades de aprendizaje de estudiantes con trastorno del espectro autista, utilizando materiales ya reconocidos y validados. En el estudio participaron el subdirector de la unidad educativa, profesores regentes, profesores de apoyo y profesores de apoyo especializados. La formación se organizó mediante una introducción teórica básica sobre la TEA, presentación de la escala, su aplicación y análisis de datos. A partir del estudio de la escala HaSA, se busca insertar intervenciones que tengan evidencia de efectividad en el contexto educativo, integrando la experiencia educativa con la mejor evidencia externa, respetando los atributos necesarios para ser definidos como evidencia científica. Son caminos empíricos, potencialmente efectivos, hasta que se demuestre lo contrario, capaces de superar las barreras de la mera matriculación del estudiante con TEA.

Palabras clave: Enseñanza; TEA; Escala de valoración; Prácticas basadas en evidencia; Educación inclusiva.

\section{Introdução}

O Transtorno do Espectro Autista (TEA) é, muitas vezes, uma condição altamente incapacitante, caracterizada por prejuízo clinicamente significativo nos domínios da comunicação e do comportamento, apresentando aproximação social anormal, pouco interesse por pares e prejuízos na conversação. Para classificar a gravidade do TEA, a Associação Americana de Psiquiatria (DSM-5) utiliza o nível de dependência provocado pelo autismo no indivíduo, e pode ser classificado pelos graus 1, leve; grau 2, moderado; e 3, severo (Liberalesso, 2020).

Seguindo as diretrizes do DSM-5 (2014), os critérios para o diagnóstico do TEA foram divididos em dois grandes grupos: (a) déficits persistentes na comunicação e na interação social verbal e não verbal em múltiplos contextos e (b) padrões restritos e repetitivos de comportamento, interesses ou atividades. No Brasil, o diagnóstico do autismo segue a diretriz da Organização Mundial da Saúde (OMS), através do Código Internacional de Doenças (CID 10), de 1999, onde se encontra classificado dentro dos Transtornos Invasivos do Desenvolvimento.

Enquanto isso, nas Ciências Humanas e na Educação, em particular, teorias procuram explicar determinado fenômeno de forma abrangente, a partir de um conjunto de ideias ou hipóteses de trabalho (Elacqua et al, 2015).

Nessa perspectiva na prática da educação inclusiva de alunos com diagnóstico de TEA, é preciso que se estimule a cultura do conhecimento amplo, profundo e compartilhado dos achados científicos que envolvam o que realmente funciona para o aluno com autismo e relacioná-los no contexto em que se apresenta: a escola. Seja para formular políticas públicas, seja para tomar decisões sobre ensino ou avaliação do atendimento escolar na sala de aula.

Na contramão de teorias, com pouca ou nenhuma comprovação científica, aliada a influência do movimento da medicina baseada em evidências surgido nos anos 70 e que ganhou força nos anos 90 no Canadá (Sackett et al, 1996), pesquisadores americanos criaram grupos de estudos científicos, dedicados a revisar sistematicamente, práticas com evidências no tratamento e educação da pessoa com autismo, contribuindo nas políticas públicas de educação inclusiva nos EUA.

O resultado desse movimento nos EUA, permitiu que só fosse oferecido às pessoas com autismo, no âmbito clínico ou educacional, práticas com evidências cientificamente comprovadas como eficazes, através de programas como No Child Left Behind (2001).

Apesar de sabermos que as decisões de políticas públicas não são apenas ou totalmente racionais, e que a ciência não é infalível, é imperativo que a educação inclusiva, tome decisões com base em informações válidas, para fugir de ideologias, 
pressões políticas, "achismos” e modismos (Elacqua et al, 2015).

\section{Método}

\section{Considerações éticas}

O estudo foi aprovado pelo Comitê de Ética e Pesquisa, da Universidade Federal Fluminense, conforme Parecer de número CAAE 20122019.0.0000.8160 e as atividades se iniciaram após a assinatura do Termo de Consentimento Livre e Esclarecido.

\section{Participantes}

A capacitação foi conduzida com dez agentes educacionais. Sendo seis professores da Educação Infantil, uma pedagoga, uma professora de atendimento educacional especializado, uma professora de apoio e a vice-diretora. Todos os profissionais participantes exercem função no segmento que abrange a faixa etária beneficiada com estimulação e intervenção precoce conforme apresentado no Quadro 1.

Quadro 1: Qualificação do grupo de agentes educacionais participantes do curso de capacitação.

\begin{tabular}{|c|c|c|c|}
\hline IDENTIFICAÇÃO & QUALIFICAÇÃ̃O & NÍVEL FORMAÇÃO & FUNÇÃ̃O \\
\hline $\mathrm{P} 1$ & Professora & Graduação & Prof. Ed. Infantil (GREI $\left.{ }^{1} 3\right)$ \\
\hline $\mathrm{P} 2$ & Professora & Pós-Grad. Lato-Sensu & Prof. Ed. Infantil (GREI 4) \\
\hline P3 & Professora & Graduação & Prof. Ed. Infantil (GREI 3) \\
\hline $\mathrm{P} 4$ & $\begin{array}{l}\text { Professora de Apoio Ed. } \\
\text { Especializado }\end{array}$ & Pós-Grad. Lato-Sensu & Prof. Apoio Ed. Esp. todas as turmas \\
\hline P5 & Professora & Pós-Grad. Lato-Sensu & Prof. Ed. Infantil (GREI 5) \\
\hline P6 & Professora de Apoio & Graduação & Prof. Apoio todas as turmas \\
\hline P7 & Professora 1 & Pós-Grad. Lato-Sensu & Prof. Ed. Infantil (GREI 5B) \\
\hline P8 & Pedagoga & Graduação & Pedagogo \\
\hline P9 & Diretora Adjunta & Pós-Grad. Lato-Sensu & Diretor Adjunto \\
\hline P10 & Professora & Pós-Grad. Lato-Sensu & Prof. Ed. Infantil (GREI 5) \\
\hline
\end{tabular}

Fonte: Arquivo pessoal.

\section{Situação e materiais}

A pesquisa foi conduzida na Unidade Municipal de Educação Infantil Almir Garcia, localizada no bairro do Maceió, no município de Niterói. Em decorrência da situação de isolamento provocada pela pandemia, outras três escolas que participariam do estudo, não puderam participar do estudo piloto da capacitação com uso do protocolo e o número da amostra da pesquisa não pode ser maior.

Como materiais, foram utilizados a Escala Pedagógica de Avaliação das Habilidades Sociais e Acadêmicas para Alunos com TEA, caneta, lápis preto e borracha, além dos slides com apresentação do curso de formação.

\section{Escala Pedagógica de Avaliação das Habilidades Sociais e Acadêmicas para Alunos com TEA - HaSA Por que criá-la?}

No ensino inclusivo, tem se discutido que agentes educacionais devem estar devidamente capacitados para que a prática educacional alcance as mais diversas necessidades do aluno com deficiência. Para que se alcance esse feito, depende- 
se, cada vez mais, de formações práticas, através de protocolos de avaliação de habilidades, que viabilizem aos agentes educacionais o conhecimento da neurodiversidade que contempla seu aluno.

O uso da Escala Pedagógica para Avaliação das Habilidades Acadêmicas e Sociais para Alunos com Transtorno do Espectro Autista por uma equipe pedagógica foi possível, através da experiência de uma formação continuada para capacitação de agentes educacionais de uma Unidade Municipal de Educação Infantil do Município de Niterói.

A Escala HaSa, foi elaborada como produto de conclusão do Mestrado Profissional em Diversidade e Inclusão pela Universidade Federal Fluminense com a finalidade de avaliar as habilidades de aprendiz do aluno no transtorno do espectro autista, inicialmente com o título provisório de Protocolo de Avaliação Sócio-Acadêmica para Atendimento Escolar de Alunos Autistas em Sala de Aula.

Participaram do estudo, a vice-diretora da unidade educacional, professores regentes, professores de apoio e professor de apoio especializado. A formação foi organizada através de uma introdução teórica básica sobre o TEA, apresentação da escala, aplicação e análise dos dados, bem como avaliação da usabilidade da Escala para o contexto escolar e desenvolvimento do aluno com TEA.

No âmbito legal, Pimenta (2019), lembra-nos que desde que, em dezembro de 2012, foi promulgada a Política Nacional de Proteção dos Direitos da Pessoa com Transtorno do Espectro do Autismo - Lei 12.764 / 2012, conhecida popularmente como Lei do Autismo ou Lei Berenice Piana, em homenagem à mãe que se dedicou a instituí-la. Nesse documento, a pessoa com TEA é considerada pessoa com deficiência, para todos os efeitos legais.

Apesar das divergências no campo clínico quanto a criança com TEA apresentar, ou não, uma deficiência, a importância da lei remete aos direitos legais adquiridos para esses sujeitos: o acesso aos serviços de assistência social oferecidos pelo Estado, a garantia de entrada na escola como aluno com deficiência, a inclusão nas políticas de saúde, abrangendo o tratamento por equipe multidisciplinar, o diagnóstico e a intervenção precoces, como também os direitos listados pelo Estatuto da Pessoa com Deficiência - Lei Brasileira de Inclusão da Pessoa com Deficiência no 13.146/15 (Brasil, 2015): o acesso à residência inclusiva, ao ensino profissionalizante, ao mercado de trabalho e à previdência social, dentre outros.

A Lei $n^{\circ} 13.146 / 15$ configura-se como mais um instrumento que surge para compor as bases legais das prerrogativas destinadas à efetivação da política de inclusão brasileira. Teve o objetivo de assegurar e promover, em condições de igualdade, o exercício dos direitos e das liberdades fundamentais da pessoa com deficiência, visando à sua inclusão social e ao pleno exercício da cidadania. Essa lei traz, em si, uma inovação no modo de se pensar a pessoa com deficiência. Define a deficiência enfatizando, sobremaneira, o papel do ambiente, que pode se mostrar facilitador ou dificultador à transposição das barreiras que impedem a inclusão desses sujeitos.

No contexto escolar, as habilidades de aprendiz são comportamentos normalmente aprendidos, no curso das interações sociais, sobretudo com pares. Em pessoas com diagnóstico de TEA, essas habilidades são notadamente irregulares, pois prevalecem características marcantes do quadro clínico do TEA, manifestados através de comportamentos restritos, déficits na interação social recíproca e falhas na comunicação social.

A inclusão escolar de aprendizes com TEA no sistema regular de ensino nacional envolve a participação de diversos agentes educacionais. De tal modo, o processo de inclusão escolar prevê uma parceria entre o professor da Educação Especial e o professor responsável pela sala de aula, com o propósito de construir um currículo adaptado que contemple objetivos pedagógicos similares, porém, com estratégias de ensino diferenciadas para cada contexto (Brasil, 2008).

Contraditoriamente elaborar essas estratégias é o motivo de maior dificuldade para o professor de sala de aula e para o professor educacional especializado que já sofre com muitas atribuições do modelo centralizador e ultrapassado de atendimento educacional especializado na perspectiva inclusiva da escola regular. Não há na estrutura ofertada hoje, pelo sistema educacional inclusivo, um instrumento que conecte a equipe pedagógica e promova uma prática descentralizada do 
professor educacional especializado, para a atuação do professor regente de sala de aula e que se estenda ao professor de apoio e, envolva, também, os outros agentes educacionais, como o pedagogo e o orientador educacional.

Sabe-se que o autismo pode ocorrer em qualquer classe social, raça ou cultura, sendo que cerca de 65 a $90 \%$ dos casos, estão associados a deficiência intelectual (Gadia; Tuchman, \& Rotta, 2004). E a realidade da escola pública de ensino, é a realidade da população de baixa renda e com acesso limitado aos atendimentos especializados e baseados em evidências científicas para pessoas com diagnóstico de TEA, como a intervenção precoce.

As estimativas da prevalência do autismo têm aumentado dramaticamente. O Centro de Controle de Doenças e Prevenção do governo dos Estados Unidos da América (EUA) (CDC, 2020), divulgou novo número de prevalência de autismo: 1 para 54. O aumento é de 10\% em relação ao número anterior, de 2014, que era de 1 para 58.

O TEA possui uma extrema complexidade educacional, sendo necessário que não só professores, mas todos os agentes educacionais envolvidos no processo de inclusão estejam bem preparados para trabalhar com esses alunos, buscando alternativas adequadas às individualidades deles. E é essa complexidade que traz angústia e dificuldades no trabalho com alunos autistas (Ribeiro \& Blanco, 2015).

Ao compreender a função de cada agente educativo, o que se pode verificar é a importância de se desenvolver capacitações que propiciem e favoreçam o intercâmbio de informações entre tais instâncias para a realização do planejamento pedagógico e social com objetivos comuns (Benitez \& Domeniconi, 2014).

Por ser um modelo ainda pouco utilizado e divulgado até o momento, o uso de escalas e protocolos de avaliação no atendimento educacional especializado de alunos com TEA, e por ser tratar de um estudo inédito na rede pública de ensino no Brasil, a divulgação desse estudo não poderia ser feito em melhor momento. Seja pela relevância do tema ou na promoção de investimentos em pesquisas sobre a inclusão e escolarização do aluno com autismo a partir da capacitação instrumentalizada dos agentes educacionais, sob as premissas das Práticas Baseadas em Evidências, pois segundo Lacerda (2020): "não parece ético submeter pessoas com o Transtorno do Espectro Autista a práticas sem nenhuma demonstração de efetividade."

Precisamos continuar incentivando estudos que atestem ou contestem o aperfeiçoamento técnico de agentes educacionais através das práticas baseadas em evidências para o desenvolvimento de alunos com TEA nas escolas públicas brasileiras, e a relevância do uso de materiais, tal como a Escala Pedagógica de Avaliação das Habilidades Sociais e Acadêmicas de Alunos com TEA, como instrumento mediador das práticas educativas inclusivas, auxiliando tanto o planejamento como o atendimento educacional.

\section{Estrutura funcional da escala HaSa}

O esquema funcional da escala HaSA tem uma estrutura pensada nas práticas cientificamente comprovadas e às idéias de Lacerda (2020). Essa estrutura se inicia com a identificação do problema apresentado no comportamento do aluno, seguido pela definição de como o problema será resolvido, e na elaboração de uma solução para o mesmo. Nesse caso, será determinado como o problema será solucionado, através dos procedimentos e meios para fazê-lo, como metas, estratégias e recursos.

Logo, será possível medir o progresso do aluno e avaliar o resultado do trabalho desenvolvido, resultando em uma educação inclusiva baseada num saber especializado (Figura 1). 
Figura 1: Estrutura Funcional da Escala HaSA

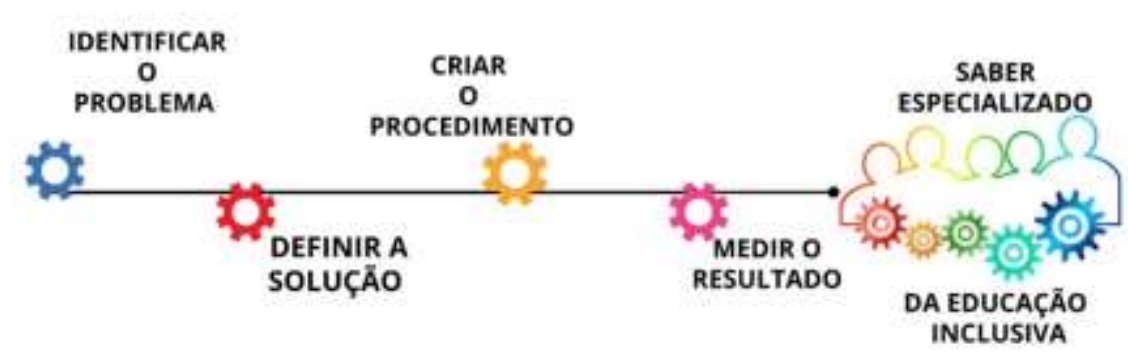

Fonte: Torres, Lione, Caminha, Domiciano (2021)

A estrutura da escala HaSA permite, através da identificação do problema apresentado, a organização das informações colhidas, definição do procedimento de intervenção, escolha da melhor abordagem de intervenção para solucionar o problema e acompanhamento dos resultados do atendimento educacional especializado realizado.

\section{Referencial Utilizado}

A construção da Escala de Avaliação das Habilidades Sociais e Acadêmicas de Alunos com Transtorno do Espectro Autista se deu inicialmente, a partir de pesquisa bibliográfica desta área específica, de instrumentos e escalas de avaliação, como Cartilha da Saúde da Criança (Min. da Saúde, 2005), CARS Childhood Autism Rating Scale (2008), ATA - Escala de Avaliação de Traços Autísticos (1999), PROTEA - Protocolo de Avaliação Comportamental para Crianças com Suspeita de TEA - Versão Revisada-Não-Verbal (2018), Protocolo de Avaliação do Desenvolvimento Sintático (2000), PROC - Protocolo de Observação Comportamental (2004), Escala de Avaliação do Comportamento Adaptativo de Vineland (2019) e PEP-R Perfil Psico educacional Revisado (1990). A seleção dos materiais utilizou os descritores "protocolo de avaliação para pessoas com TEA", "escalas de rastreio para traços autísticos". Os bancos de dados consultados foram a Plataforma Scielo, Capes e PubMed. Em termos teóricos, deu-se maior destaque àqueles com premissas cognitivas, comportamentais, desenvolvimentistas e educacionais.

Sob influência dos instrumentos mais utilizados nas escalas de rastreio e diagnóstico de TEA utilizados, optou-se por avaliar um conjunto de sintomas que abrangem as áreas que destacam maior irregularidade no comportamento do indivíduo com TEA: comportamento, comunicação verbal e não-verbal, interesses, perfil sensorial, linguagem, área motora, compreensão, raciocínio, comportamento colaborativo e funcional.

Essa decisão foi sustentada pela sintomatologia do transtorno que se apresenta em dois grupos característicos: 1déficits clinicamente significativos e persistentes na comunicação social e nas interações sociais e 2- padrão de comportamentos repetitivos e estereotipados (Fuentes et al, 2014).

\section{Curso de Capacitação: aplicação experimental da Escala HaSa}

A capacitação foi conduzida com dez agentes educacionais. Sendo seis professores da Educação Infantil, uma pedagoga, uma professora de atendimento educacional especializado, uma professora de apoio e a vice-diretora. Todos os profissionais participantes exercem função no segmento que abrange a faixa etária beneficiada com estimulação e intervenção precoce.

O método utilizado para o uso experimental da escala, após aprovação do Comitê de Ética e Pesquisa, da Universidade Federal Fluminense, conforme Parecer de número CAAE 20122019.0.0000.8160, envolveu a assinatura do 
Termo de Consentimento Livre e Esclarecido, seguido da qualificação dos participantes (Quadro 2), situação e materiais e resultados.

Quadro 2: Qualificação do grupo de agentes educacionais participantes do Curso de Capacitação.

\begin{tabular}{|c|c|c|c|}
\hline IDENTIFICAÇÃO & QUALIFICAÇÃ̃O & NÍVEL FORMAÇÃO & FUNÇÃO \\
\hline $\mathrm{P} 1$ & Professora & Graduação & Prof. Ed. Infantil (GREI 3) \\
\hline $\mathrm{P} 2$ & Professora & Pós-Grad. Lato-Sensu & Prof. Ed. Infantil (GREI 4) \\
\hline P3 & Professora & Graduação & Prof. Ed. Infantil (GREI 3) \\
\hline $\mathrm{P} 4$ & $\begin{array}{l}\text { Professora de Apoio Ed. } \\
\text { Especializado }\end{array}$ & Pós-Grad. Lato-Sensu & Prof. Apoio Ed. Esp. todas as turmas \\
\hline P5 & Professora & Pós-Grad. Lato-Sensu & Prof. Ed. Infantil (GREI 5) \\
\hline P6 & Professora de Apoio & Graduação & Prof. Apoio todas as turmas \\
\hline P7 & Professora 1 & Pós-Grad. Lato-Sensu & Prof. Ed. Infantil (GREI 5B) \\
\hline P8 & Pedagoga & Graduação & Pedagogo \\
\hline P9 & Diretora Adjunta & Pós-Grad. Lato-Sensu & Diretor Adjunto \\
\hline P10 & Professora & Pós-Grad. Lato-Sensu & Prof. Ed. Infantil (GREI 5) \\
\hline
\end{tabular}

Fonte: Arquivo pessoal.

A pesquisa foi conduzida na Unidade Municipal de Educação Infantil Almir Garcia, localizada no bairro do Maceió, no município de Niterói. Em decorrência da situação de isolamento provocado pela pandemia, outras três escolas que participariam do estudo, não puderam participar do estudo piloto da capacitação com uso da escala e o número da amostra da pesquisa não pode ser maior.

Como materiais, foram utilizados a Escala Pedagógica de Avaliação das Habilidades Sociais e Pedagógicas para Alunos com Transtorno do Espectro Autista, caneta, lápis preto e borracha, além dos slides com apresentação do curso de formação.

\section{O processo do Curso}

O processo de aplicação do curso (Figura 2) envolveu uma metodologia básica, com uma breve contextualização do tema autismo, seguido da apresentação da escala HaSA. Um estudo de caso foi usado para facilitar a identificação das manifestações comportamentais de uma criança com TEA.

Por fim, foi feita análise dos resultados da aplicação da escala e cada agente educacional avaliou a escala HaSA. 
Figura 2: Processo do curso de aplicação da escala HaSa.

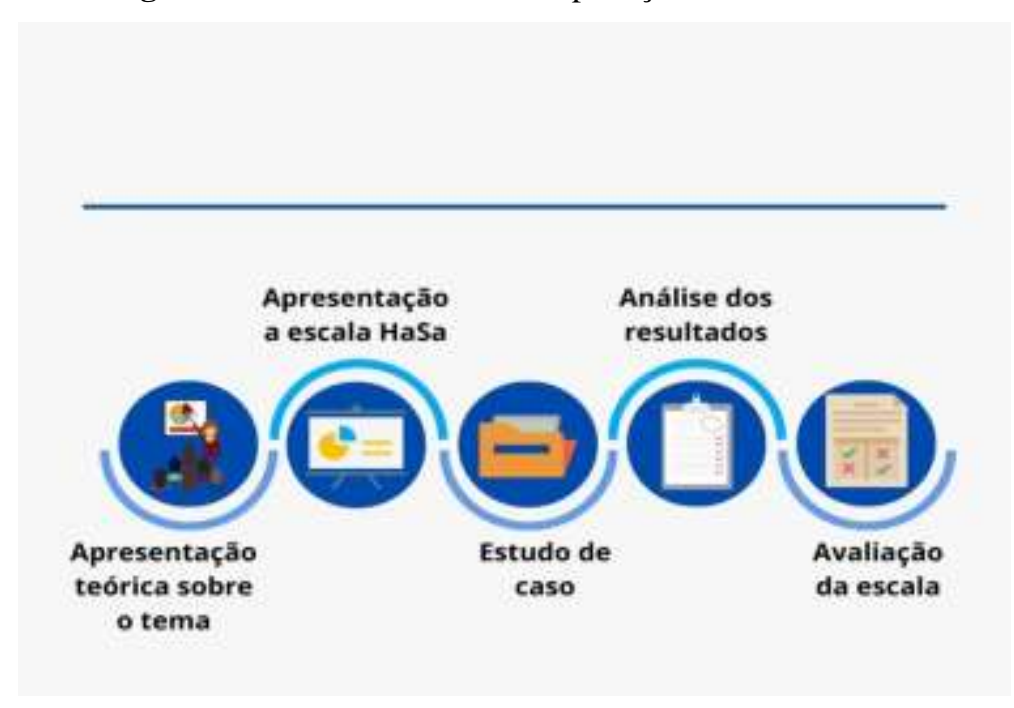

Fonte: Torres, Lione, Caminha, Domiciano (2021).

A didática utilizada no curso contribuiu para um melhor entendimento por parte dos agentes educacionais sobre a importância na trajetória de identificação das manifestações neurodiversas do aluno no espectro do autismo ao atendimento educacional especializado.

\section{Metodologia do curso de capacitação para aplicação da escala}

A capacitação foi aplicada em uma escola com a participação de P1, P2, P3, P4, P5, P6, P7, P8, P9 e P10. A formação foi dividida em sete partes, num período de duas horas, sendo:

1. Breve apresentação conceitual do Transtorno do Espectro do Autismo, onde a fundamentação teórica considerou conceitos do DSM-5 e dados da OMS (2010); onde foram retiradas dúvidas de cada profissional; justificativa da apresentação do trabalho, como produto de uma pesquisa de mestrado;

2. Objetivo da Capacitação;

3. Definição e especificação técnica da Escala Pedagógica de Avaliação das Habilidades Sociais e Acadêmicas para Alunos com Transtorno do Espectro Autista: definição, público-alvo, finalidade, normas de uso e correção;

4. Apresentação de estudo de caso com aplicação da Escala pelos agentes educacionais envolvidos;

5. Correção e Análise dos Resultados;

6. Conclusão: desdobramentos dos resultados obtidos com a Escala para o Plano de Ensino Individualizado e

7. Avaliação da escala.

Cada professor preencheu a Escala Pedagógica de Avaliação das Habilidades Sociais e Acadêmicas para Alunos com Transtorno do Espectro Autista.

Ao término da capacitação, os professores participantes responderam um questionário com o feedback sobre a validade de uso da Escala no contexto escolar, sua relevância para o atendimento educacional inclusivo na prática do professor e para o desenvolvimento do aluno com TEA.

Com o propósito de complementar a análise sobre os efeitos da capacitação, no final do questionário de feedback, os professores avaliavam de forma geral a Escala Pedagógica de Avaliação das Habilidades Sociais e Acadêmicas para Alunos com Transtorno do Espectro Autista, assim como a capacitação na formação realizada. 


\section{Resultados}

Após aplicação da escala pelo grupo de agentes educacionais, foi conduzida uma análise dos registros feitos pelos agentes educacionais na escala preenchida, e seus dados foram transferidos para o gráfico ilustrativo da escala (Quadro 3). No gráfico, foi pintada a pontuação total obtida em cada dimensão avaliada na escala.

Quadro 3: Demonstração do Gráfico Ilustrativo - Parte integrante da Escala Pedagógica de Avaliação das Habilidades Sociais e Acadêmicas para Alunos com Transtorno do Espectro Autista.

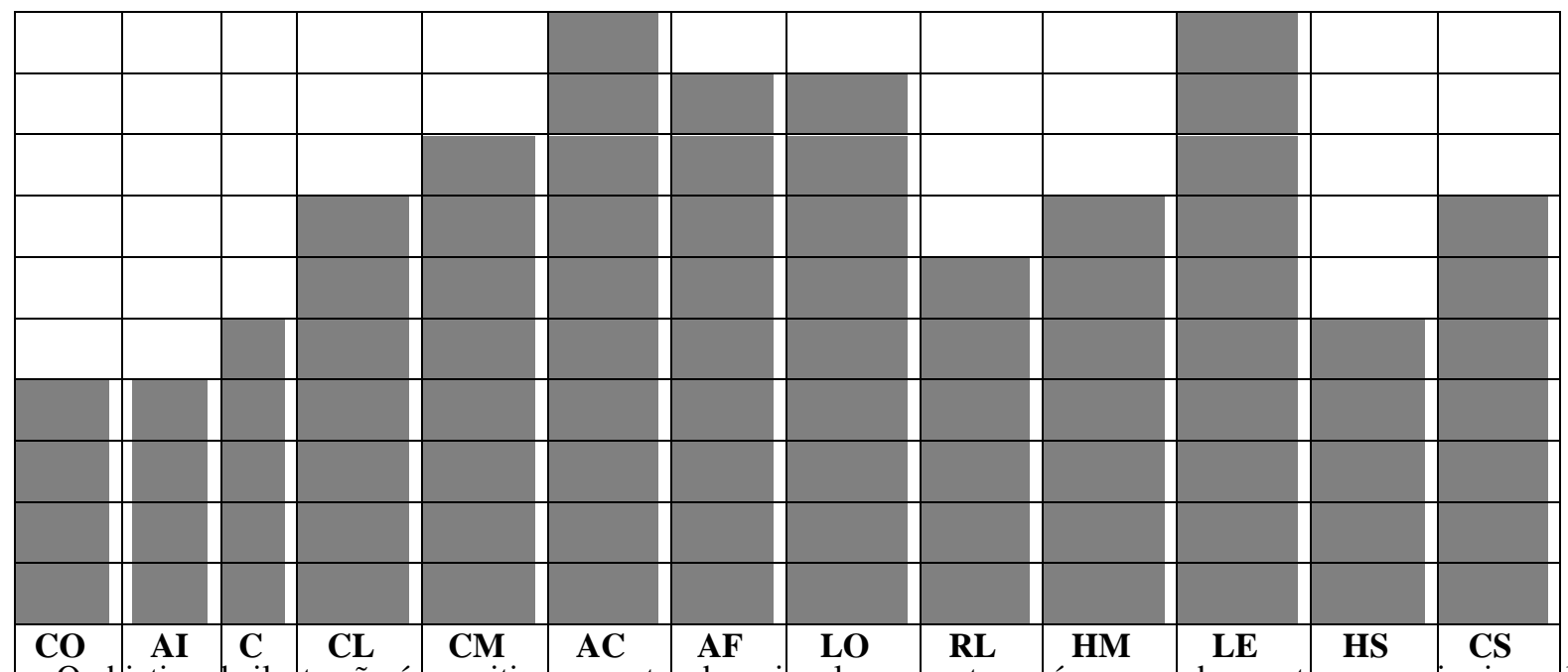

O objetivo da ilustração é permitir do agentel educacibnal representar as áreas que demonstraram maior irregularidade no comp

A nomenclatura das áreas avaliadas foram abreviadas, para melhor se ajustarem ao layout do gráfico ilustrativo, e obedecem sua ordem de apresentação na escala: I) CO: Comportamento; II) AI: Área de Interesse; III) C: Compreensão; IV) CL: Colaboração; V) CM: Comunicação; VI) AC: Atividades de Autocuidado; VII) AF: Atividades Funcionais; VIII) LO: Linguagem Oral; IX) RL: Raciocínio Lógico-Matemático; X) HM: Habilidades Motoras; XI) LE: Linguagem Escrita; XII) HS: Habilidades Sociais e Adaptativas e XIII) CS: Características Sensoriais. Fonte: Arquivo pessoal.

As informações ilustradas no gráfico serviram de base para elaboração do plano de ensino individualizado, elaborado em conjunto por todos os agentes educacionais e o pesquisador.

Ao elaborar o PEI, a partir dos desdobramentos das áreas avaliadas na escala (Quadro 4), as irregularidades identificadas foram divididas em metas de longo prazo, curto prazo e estratégias de ensino. Para as metas, foram consideradas hierarquicamente, àquelas necessárias ao desenvolvimento das três áreas identificadas com maior irregularidade no comportamento do aluno apresentado por meio de caso clínico durante a capacitação. 
Quadro 4: Desdobramentos dos resultados da escala para elaboração do plano de ensino individualizado.

\begin{tabular}{|c|c|c|c|}
\hline $\begin{array}{l}\text { META LONGO } \\
\text { PRAZO } \\
\text { (O que precisa } \\
\text { aprender) } \\
\end{array}$ & $\begin{array}{l}\text { META CURTO PRAZO } \\
\text { (o mínimo a aprender) }\end{array}$ & $\begin{array}{l}\text { ESTRATÉGIAS } \\
\text { (como vou ensinar) }\end{array}$ & $\begin{array}{l}\text { AVALIAÇÃO } \\
\text { (se aprendeu a } \\
\text { habilidade) }\end{array}$ \\
\hline $\begin{array}{l}\text { Habilidades com } \\
\text { maior irregularidade } \\
\text { na área de auto- } \\
\text { cuidado } \\
\text { (AC) }\end{array}$ & $\begin{array}{l}\text { 1. Aprender a beber água sem } \\
\text { ajuda, } 2 \text {. Aprender a fazer } \\
\text { xixi no vaso, } 3 \text {. Ajudar ou Se } \\
\text { vestir sozinho }\end{array}$ & $\begin{array}{l}\text { Usar pista visual } \\
\text { com cartões de } \\
\text { ação }\end{array}$ & $\begin{array}{l}\text { 1. sim. Quando? } \\
\text { 2. não } \\
\text { 3. aprendendo }\end{array}$ \\
\hline $\begin{array}{c}\text { Habilidades com } \\
\text { maior irregularidade } \\
\text { na área da Linguagem } \\
\text { Expressiva (LE) }\end{array}$ & $\begin{array}{l}\text { 1. Aprender a pedir Água, } 2 . \\
\text { Aprender a pedir para fazer } \\
\text { xixi }\end{array}$ & $\begin{array}{l}\text { 1. Usar pista visual } \\
\text { com cartões de } \\
\text { ação }\end{array}$ & 1. aprendendo \\
\hline $\begin{array}{c}\text { Habilidades com } \\
\text { maior irregularidade } \\
\text { nas Atividades } \\
\text { Funcionais } \\
\text { (AF) }\end{array}$ & $\begin{array}{l}\text { 1. Aprender a Identificar sua } \\
\text { sala de aula, banheiro e pátio, } 2 \text {. } \\
\text { Aprender a se orienta r no } \\
\text { espaço escolar, } 3 \text {. Compreender } \\
\text { início, meio e fim da atividade }\end{array}$ & $\begin{array}{l}\text { 1. Usar agenda visual } \\
\text { com ações das } \\
\text { tarefas usadas na } \\
\text { rotina escolar }\end{array}$ & 1. aprendendo \\
\hline
\end{tabular}

Fonte: Arquivo pessoal.

\section{Análise quantitativa da aplicação da Escala Pedagógica de Avaliação das Habilidades Sociais e Acadêmicas para Alunos} com Transtorno do Espectro Autista

A Escala Pedagógica de Avaliação das Habilidades Sociais e Acadêmicas para Alunos com Transtorno do Espectro Autista tem como objetivo tornar mais técnica e objetiva a atuação do agente educacional com seu aluno com Transtorno do Espectro Autista em sala de aula, através da identificação de padrões regulares e irregulares deles.

A partir da experiência obtida no curso de capacitação, foi apresentada uma análise quantitativa (Quadro 5) da sua aplicação com o grupo de agentes educacionais participantes da Unidade Municipal de Educação Infantil Almir Garcia, no bairro do Maceió, município de Niterói.

Quadro 5: Respostas dos participantes ao questionário de feedback.

\begin{tabular}{|c|c|c|}
\hline Categorias & Sim & Não \\
\hline Dificuldade na utilização & $9(90 \%)$ & $1(10 \%)$ \\
\hline Dificuldade inicial & $3(30 \%)$ & $7(70 \%)$ \\
\hline Dificuldade na pontuação & $5(50 \%)$ & $5(50 \%)$ \\
\hline $\begin{array}{c}\text { Utilidade da Escala para o professor em } \\
\text { sala de aula }\end{array}$ & $10(100 \%)$ & 0 \\
\hline $\begin{array}{l}\text { Validade da Escala para o } \\
\text { desenvolvimento infantil }\end{array}$ & $10(100 \%)$ & 0 \\
\hline
\end{tabular}

Fonte: Arquivo pessoal.

A aplicação do questionário aos agentes educacionais possibilitou identificar opiniões quanto às dificuldades de utilização do instrumento, bem como à sua utilidade para o trabalho docente em sala de aula e o desenvolvimento infantil. Além disso, fez-se uma análise qualitativa baseada na experiência individual de cada participante sobre a Escala Pedagógica de Avaliação das Habilidades Sociais e Acadêmicas de Alunos com TEA e quantitativa sobre a relevância do produto para a prática docente e desenvolvimento do aluno com TEA. 


\section{Análise qualitativa do uso da Escala Pedagógica de Avaliação das Habilidades Sociais e Acadêmicas para Alunos com} TEA

Os agentes educacionais contribuíram ainda com suas avaliações e perspectivas sobre a qualidade da Escala e opinaram sobre sua validade na educação básica de ensino, respondendo ao questionário de feedback do material utilizado, conforme depoimentos a seguir:

No que diz respeito a opinião geral dos agentes educacionais sobre o a relevância da escala, foi dito:

"Sim. Pois auxiliará o trabalho que será realizado, e possíveis encaminhamentos para os profissionais da área." (P1) "Sim."

(P2, P3 e P4)

"Sim. Com certeza contribuirá muito." (P5)

"Acredito que sim" (P6).

"Acho o material muito útil, pois ao facilitar a nossa observação do aluno, propicia a realização de um trabalho mais direcionado e enriquecedor." (P7)

"Sim. Este material poderá auxiliá-lo no seu plano de ensino com propostas mais adequadas aos alunos e na avaliação." (P8)

“Com toda certeza!” (P10)

Ao fazer uma análise das expectativas ao desenvolvimento de seus alunos com TEA após utilização da escala para identificação dos comportamentos irregulares, as participantes comentaram:

“Acredito que sim, pois metas serão traçadas para cada dificuldade." (P1)

"Sim." (P2, P3, P4)

"Acho que sim. Pois ajuda o professor a seguir alguns caminhos." (P5)

"Com certeza, pois tendo os objetivos claros é possivel observar o desenvolvimento." (P6)

"Acredito que o trabalho com o uso da Escala pode contribuir para o seu desenvolvimento." (P7)

"Acredito que sim, se houver parceria entre a família e escola para questões que a escola não tem como resolver." (P8)

"Sim." (P9, P10)

Impressões sobre a pontuação da escala foi o momento que gerou maior dúvida. Uma parte das participantes não se sentiu segura com os critérios utilizados para pontuar, enquanto outras demonstraram dificuldade inicial, mas a superaram ao final. Responderam sobre dificuldades para usá-la:

"Sim. Em relação a pontuação, a dar um número para cada situação". (P1)

"No início sim." (P2)

"Sim. por conta da numeração." (P3)

"Um роисо." (P5)

"Sim em relação à pontuação." (P6)

"No início senti um pouco de dificuldade por se tratar de um material novo." (P7)

"Sim. A numeração diferente nos itens." (P8) 
"No início sim, mas de maneira que vai fazendo, torna-se mais fácil." (P9)

"Somente para pontuar." (P10)

As dificuldades apresentadas e registradas no questionário de avaliação pelos agentes educacionais participantes com relação a pontuação da escala, nos leva a refletir sobre as metodologias aplicadas às formações continuadas e geram duas hipóteses sobre a dificuldade com a pontuação do material. Será a falta de contato na graduação e inexperiência do professor com conceitos técnicos envolvidos, instrumentos de avaliação ou da tarefa prática em si, para realizar os registros do comportamento dos alunos que influenciou suas respostas negativas à pontuação da escala? Ou estariam os professores acostumados com os modelos de formação onde as ideias de quem está ministrando pudessem dar conta sozinhas de suas capacitações e resistindo a nova proposta por dificuldade em vislumbrar a implementação de mudanças para um novo modelo de atendimento educacional especializado que envolvesse maior participação do professor regente?

Tudo isso nos faz pensar nos conteúdos e na forma dos cursos oferecidos aos professores nos mais diversos ambientes, nos levando então a buscar alguma explicação que ajude compreender a pouca eficiência dessas atividades de formação na mudança das práticas, mormente nas que se referem à avaliação da aprendizagem realizada pelo professor, em sala de aula com seus alunos com TEA (Rojas, 2007).

O estudo piloto com a aplicação experimental da escala pelos agentes educacionais demonstrou ser uma estratégia viável ao atendimento educacional especializado para alunos com TEA em sala de aula porque em avaliação realizada ao final da capacitação, todos os dez agentes educacionais participantes da formação continuada, mesmo diante das dificuldades demonstradas com a pontuação, disseram que gostariam de usar a Escala Pedagógica de Avaliação das Habilidades Sociais e Acadêmicas de Alunos com Transtorno do Espectro Autista com seus alunos e acreditam em sua usabilidade em sala de aula, conforme seus próprios relatos:

"Achei interessante, pois possibilita ao professor direcionar o trabalho pedagógico, atendendo as necessidades especificas de cada um." (P1)

"Achei muito pertinente, diante da realidade que vivemos dentro da sala de aula." (P2)

"Facilita a avaliação, a investigação e o planejamento." (P3)

"Uma ferramenta bastante útil, tanto para a sala de aula como também para o consultório." (P4)

"No início um pouco confuso, com o decorrer do tempo foi ficando mais fácil." (P5)

“A questão da numeração no primeiro momento pareceu confusa." (P6)

"A Escala contribuiu para uma observação mais atenta do aluno e apresenta uma linguagem apropriada para a realidade escolar" (P7)

"Considero muito importante para traçar o perfil cognitivo do aluno e, assim, propor um planejamento mais adequado às suas necessidades" (P8)

"Muito bom, pois facilita muito o início do trabalho individualizado com o aluno." (P9)

"Excelente." (P10)

Sabemos que o que dá certo para uma criança com TEA pode não dar certo para outra. Porém, sabemos também ser verdade que existem princípios específicos do aprendizado que se aplicam a todos os empreendimentos humanos. A meta é observar e encontrar o padrão específico de reação que cada criança exibe, e tomar isso como o ponto de partida (Grandin \& Scariano, 1999). 
Por fim, segundo o relato das participantes, a formação continuada, com a proposta do curso de capacitação para aplicação da Escala Pedagógica de Avaliação das Habilidades Sociais e Acadêmicas de Alunos com Transtorno do Espectro Autista, foi de grande importância, pois apesar das dificuldades com a pontuação, puderam conhecer e administrar um recurso metodológico diferente para atender educacionalmente seu aluno com TEA, percebendo, sobretudo, que para um atendimento educacional especializado eficiente precisam, além de um trabalho coordenado e descentralizado entre todos os agentes educacionais envolvidos, ter um ponto de partida; como lembrado por Grandin (1999), oferecendo, assim melhores maneiras de atender às necessidades individuais de seus alunos.

"O trabalho foi bastante produtivo; que outras escolas possam reconhecer a importância de uma formação como essa." (P1)

"Ao invés de número colocar sim ou não". (P2)

"Informações mais claras para o estudo de caso". (P3)

"A questão da pontuação poderia ser mais detalhada". (P6)

"Em relação a pontuação das questões". (P8)

“Esse material poderia ser compartilhado" (P9)

"Repensar a forma de pontuar". (P10)

\section{Discussão}

O estudo experimental para uso da Escala HaSa teve como objetivo criar e avaliar uma capacitação destinada aos agentes educacionais de uma unidade municipal de educação infantil, através da aplicação da escala, de modo a refletir sobre o uso de um instrumento facilitador que descentralizasse o atendimento educacional especializado na prática inclusiva da educação básica apenas na perspectiva da sala de recursos multifuncional.

O uso da Escala HaSa, proposto na capacitação dos agentes educacionais, e descrito neste artigo, pode ser considerado como uma alternativa para a queixa demonstrada em diversos estudos que relatam sobre as dificuldades que os agentes educacionais e professores, de modo geral apontam, em relação às suas respectivas formações acadêmicas para atuarem no panorama inclusivo prático: (Rojas, 2007; Pimenta, 2019; Gadia, Tuchman, \& Rotta, 2004; Ribeiro \& Blanco, 2015; Benitez \& Domeniconi, 2014; Grandin \& Scariano, 1999; Lacerda, 2020).

Significa que o atendimento educacional, sob o ponto de vista da educação inclusiva especializada, se dá através do entrelaçamento da prática de TODOS os agentes educacionais: professor de apoio especializado, professor de apoio, pedagogo, orientador educacional; e não se restringe ao professor de atendimento educacional especializado ou a sala de recursos multifuncional.

O professor de apoio especializado acaba sendo sobrecarregado com a demanda de todos os alunos com deficiência na escola, que assim como o TEA, tem necessidades educacionais específicas, dentro da sua neurodiversidade.

O ensino inclusivo exige que os professores estejam, além de abertos, capacitados a neurodiversidade e tenham a consciência de que todos os estudantes aprendem relacionando a sala de aula a suas experiências de vida.

Embora muitas oportunidades de formação de professores e de aprendizagem profissional sejam bem elaboradas, pontos de vista enviesados sobre alguns estudantes como deficientes ou incapazes de aprender significa que os professores podem ter dificuldade para ver que a capacidade de aprender de cada um não tem limites (Unesco, 2020).

Cada agente educacional participante, pode ampliar por meio da capacitação, seu entendimento sobre as necessidades neurodiversas o aluno com TEA, e sobre como a aquisição desse conhecimento implica no desenvolvimento cognitivo, cognitivo-verbal e adaptativo, com implicações positivas ou negativas no comportamento social do aluno. 
Ao serem observadas as condições que são oferecidas aos agentes educacionais, para a aprendizagem do complexo procedimento da avaliação das características neurodiversas do aluno, vê-se que sua formação inicial na graduação não a contempla. Há poucas oportunidades consistentes de formação continuada sobre a temática e os críticos que vêm escrevendo sobre ela, mais têm denunciado seus problemas do que oferecido soluções realistas, e as abordagens disponíveis aos professores sobre o que deva ser a avaliação não são concordes entre si nem estão completamente estruturadas para a imediata aplicação em sala de aula (Rojas, 2007).

Cada agente educacional foi capacitado dentro do contexto proposto pela formação e vislumbraram o potencial do uso da escala no contexto natural da escola, e que somadas ao intercâmbio das funções desempenhadas por cada um, enriqueceriam o trabalho conjunto com o atendimento educacional especializado.

Outro ponto muito importante a se esclarecer, é que o objetivo da Escala Pedagógica de Avaliação das Habilidades Sociais e Acadêmicas de Alunos com TEA, não é substituir ou propor novos critérios diferentes daqueles já utilizados por pesquisadores precursores na área de estudo. Todavia, crê-se que sua utilização poderá ser realizada por agentes educacionais treinados e supervisionados, e necessária as suas práticas de ensino inclusivo em sala de aula e no contexto escolar.

A escala, a partir de um roteiro estruturado e baseado na identificação das características neurodiversas dos alunos com Transtorno do Espectro Autista, organiza-se num planejamento educacional, pautado na singularidade do aluno e em consonância ao previsto nos Parâmetros Curriculares Nacionais (Brasil, 1997).

De modo geral, os dados coletados, quando tomados conjuntamente, revelam alterações nas áreas apresentadas, indicando possíveis caminhos que o professor poderá seguir para mediar a aprendizagem de seu aluno no contexto escolar (Bosa \& Salles, 2018).

Acredita-se que a capacitação proposta na formação continuada para os agentes educacionais da unidade de educação infantil Almir Garcia, no município de Niterói, possa ter contribuído em alguma medida na operacionalização de estratégias inclusivas descentralizadas da equipe pedagógica da unidade escolar, de modo a atender os diferentes alunos com TEA em sua neurodiversidade, de maneira colaborativa, integrativa e assertiva, através da elaboração de um Plano de Ensino Individualizado, que contemple suas necessidades e potencialidades.

É esperado que o envolvimento de toda equipe, por meio da aplicação da Escala HaSa, contribua na escolha de abordagens de intervenção educacionais mais funcionais e assertivas, para o desenvolvimento do aluno no contexto escolar, aumentando as possibilidades de manutenção das habilidades aprendidas em ambiente natural.

As mesmas estratégias de ensino atribuídas e desenvolvidas na escola podem ser trabalhadas em parceria com a família no ambiente doméstico. Esta conduta que pode contribuir na sistematização da aprendizagem em contextos diferentes, mas com os mesmos objetivos a serem alcançados.

Além disso, os resultados preliminares, demonstraram que a capacitação com o uso da Escala HaSa, pode ser considerada como uma estratégia relevante, demonstrando ser um forte argumento para a continuidade do estudo com amostra mais expressiva, promovendo a participação e o envolvimento de TODOS os agentes educacionais a respeito da educação inclusiva.

\section{Considerações Finais}

De acordo com o estudo, acredita-se que a aplicação experimental da escala HaSA, proposta na formação continuada para os agentes educacionais da Unidade Municipal de Educação Infantil Almir Garcia, no município de Niterói, possa ter contribuído, em alguma medida sobre a importância em se adotar abordagens de intervenção educacional, baseadas em evidências científicas para o aluno com TEA, a partir da identificação das manifestações comportamentais do aluno do estudo de caso. 
Por meio do intercâmbio de suas experiências e práticas, e munidos de um instrumento padronizado para a identificação de domínios e prejuízos comportamentais, os agentes educacionais, puderam elaborar um Plano de Ensino Individualizado, com os desdobramentos da escala HaSA, contemplando as necessidades e potencialidades de seus alunos com autismo.

É esperado que o envolvimento da equipe escolar, por meio da aplicação da Escala Pedagógica de Avaliação das Habilidades Sociais e Acadêmicas para Alunos com TEA, contribua na adoção de abordagens de intervenção educacionais cientificamente comprovadas para o aluno no espectro do autismo.

Essa perspectiva na prática da educação inclusiva baseada em evidências permite almejar o desenvolvimento psicossocial do aluno com TEA no contexto escolar, aumentando as possibilidades de manutenção das habilidades aprendidas na escola, também em sua casa, através do serviço de orientação educacional. Tal mudança de paradigma na educação inclusiva para o aluno com TEA, pode contribuir na sistematização da aprendizagem em contextos sociais diferentes. Além disso, como já exposto, os resultados analisados demonstram que a capacitação com aplicação experimental da escala HaSA, pode ser considerada como uma estratégia relevante, ainda que dependa da continuidade do estudo, na promoção e envolvimento de TODOS os agentes educacionais a respeito da educação inclusiva e cidadania do aluno com TEA.

Por fim, sugerimos que o tema seja cada vez mais discutido no âmbito acadêmico e da educação inclusiva, e que outros estudos sobre práticas baseadas em evidências na educação sejam desenvolvidos principalmente na educação pública, contribuindo para uma inclusão educacional mais técnica, acessível e democrática.

\section{Referências}

American Psychiatric Association. (2014). Manual Diagnóstico Estatístico de Transtornos Mentais DSM-5. Artmed.

Benitez, P. \& Domeniconi, C. (2014). Capacitação de Agentes Educacionais: Propostas de Desenvolvimento de Estratégias Inclusivas. Rev. Bras. Ed. Esp. Marília, 20 (3), 371-386.

Bosa, C. A. \& Salles, J. F. (Orgs.). (2018). PROTEA-R: Sistema de Avaliação da Suspeita do Transtorno do Espectro Autista. Vetor.

Brasil (2005). Ministério da Saúde. Secretária de Saúde. Cartilha de Saúde da Criança.

Brasil (2012). Lei 12.764 de 27 de dezembro de 2012.

Elacqua, G, et al. (2015). Educação baseada em evidências: como saber o que funciona em educação. Instituo Alfa e Beto.

Fonseca, M. E. (2007). Guiando Pais e Profissionais na Abordagem Teacch: Aspectos educacionais da pessoa com autismo. Mimeo.

Fuentes, D. M. Leandro F. C. Candida, H. P. \& Cosenza, R. M. (orgs) (2014). Neuropsicologia: teoria e prática. (2a ed.), Artmed.

Grandin, T. \& Scariano, M. M. (1999). Uma menina estranha. Companhia das Letras.

Junior, F. B. A., Kuczynski, E., Gabriel, M. R. \& Rocca, C. C. (1999). Escala de Avaliação de Traços Autísticos (ATA). Validade e Confiabilidade de uma Escala para a Detecção de Condutas Autísticas. Arq. Neuropsiquiatria, 57 (1), 23-29.

Liberalesso, P. \& Lacerda, L. (2020). Autismo: Compreensão e práticas baseadas em evidências. Marcos Valentin de Souza.

Maenner, M. J., et al. (2020). Prevalência do Transtorno do Espectro do Autismo em Crianças de oito anos. Rede de Monitoramento do Autismo e Deficiências do Desenvolvimento. http://www.cdc/mmwr/volumes/69/ss/ss6904a1.htm

Pereira, A., Riesgo, R. S. \& Wagner, M. B. W. (2008). Childhood autism: translation and validation of the Childhood Autism Rating Scale for use in Brazil. Jornal de Pediatria, 84 (6), 487-494.

Pimenta, P. R. (2019). Clínica e Escolarização dos Alunos com Transtorno do Espectro Autista. http://doi.org/10.1590/2175-623684859.

Ribeiro, E. M. A, \& Blanco, M. B. (2015). Um Estudo sobre as Propostas de Intervenção com Crianças Autistas em Sala de Aula. In Cadernos PDE: os desafios da escola pública paranaense na perspectiva do professor PDE. Secretaria de Estado da Educação do Paraná. 2-19.

Rojas, H. (2007). A Avaliação em Sala de Aula: quais as dificuldades para a formação do professor do ensino básico? Dissertação de mestrado. PUC

Rotta, N. T., Ohlweiler, L. \& Riesgo, R. S. Orgs. (2006). Transtornos de Aprendizagem. Abordagem Neurobiológica e Multidisciplinar. Porto Alegre: Artmed. Sparow, S. S., Cicchetti, D. V. \& Saulnier, C. A. (2019). Vineland-3: Escala de Comportamento Adaptativo. São Paulo. Pearson Clinical.

Tismoo (2020). EUA tem novo número de prevalência para autismo: 1 para 54. http://www.tismoo.us/destaques/eua-tem-novo-numero-de-prevalencia-de- 
Research, Society and Development, v. 10, n. 13, e207101321007, 2021

(CC BY 4.0) | ISSN 2525-3409 | DOI: http://dx.doi.org/10.33448/rsd-v10i13.21007

autismo-1-para-54.

Organização das Nações Unidas para Educação, Ciência e Cultura (2020). Inclusão e Educação: todos, sem exceção. http://www.unesdoc.unesco.org.

Yin, R. K. (2015). O estudo de caso. Bookman. 